\title{
Mediação do Professor em Investigações Estatísticas
}

\author{
Emanueli Bandeira Avi, Cátia Maria Nehring Peterson Cleyton Avi, \\ Depto de Ciências Exatas e Engenharias, DCEEng, UNIJUI \\ 98700-000, Ijui, RS \\ E-mail: emanueli.bandeira@unijui.edu.br; catia@unijui.edu.br; peterson.avi@unijui.edu.br
}

\begin{abstract}
RESUMO: $O$ presente trabalho objetiva discutir a mediação do professor em ambientes de investigação estatística, com vistas ao desenvolvimento de aprendizagens matemáticas. $O$ estudo faz parte da dissertação de Mestrado em Educação nas Ciências da primeira autora com orientação da segunda, na qual foi desenvolvida uma pesquisa empírica com um grupo de doze alunos voluntários com os quais foram realizados dez encontros. As atividades interativas realizadas foram estruturadas a partir de investigações estatísticas. $O$ entrelaçamento dos resultados empíricos com a discussão teórica trouxe à tona o potencial das atividades de cunho investigativo para a aprendizagem, bem como a importância da mediação no processo de investigação culminando no desenvolvimento de conceitos matemáticos e estatísticos.
\end{abstract}

\section{INTRODUÇÃO:}

As demandas oriundas da complexidade da sociedade atual fazem com que $o$ tratamento de dados esteja cada vez mais presente no cotidiano de todos nós. Ensinar estatística na educação básica tornou-se, portanto, uma necessidade social na qual a escola pode e deve contribuir considerando sua função de educar e instruir as novas gerações. A aprendizagem de estatística, ou seja, a formação de sujeitos estatisticamente letrados tem ampla relação com a forma como esta vem sendo ensinada na escola. Por sua característica, o tratamento de dados possibilita uma prática interdisciplinar, porém, muitas vezes, a utilização da estatística em projetos acaba enfocando somente a forma de representar dados, através de tabelas e gráficos, sem que sejam estabelecidos os significados necessários e a elaboração dos conceitos inerentes a este campo da matemática.

Definir a aprendizagem de estatística como foco dessa investigação, foi uma escolha considerando que ensiná-la na Educação Básica é importante para a formação cidadã dos estudantes. Segundo Lopes (2010), seu ensino pode ser considerado um dos grandes objetivos que os currículos de matemática devem possibilitar, bem como, deve ser ensinado desde os anos iniciais até o ensino médio.

Os PCNs (Parâmetros Curriculares Nacionais (BRASIL, 1998)) justificam o ensino de Estatística e Probabilidade, considerando que seu estudo

[...] justifica-se por possibilitar o desenvolvimento de formas particulares de pensamento e raciocínio para resolver determinadas situações problemas [...] nas quais é necessário coletar, organizar e apresentar dados, interpretar amostras, interpretar e comunicar resultados por meio da linguagem estatística (BRASIL, 1998, p.134).

Este documento trata a estatística juntamente com a probabilidade como um bloco de conteúdos e ressalta sua importância na formação crítica e humanística dos cidadãos, já que sua aprendizagem influencia nos modos de pensar dos alunos concebendo que a linguagem estatística faz parte do dia a dia da sociedade, e que os conceitos de aleatoriedade e variabilidade das situações podem possibilitar um melhor desempenho na tomada de decisões.

Para Batanero (2001, p.87), de nada adianta conhecer definições e cálculos estatísticos se não se sabe o problema relacionado a estes e nem mesmo sua influência na tomada de decisões.

Lopes e Carvalho (2009) destacam que o ensino de estatística deve se dar pela problematização, possibilitando o enfrentamento com problemas da realidade que possibilitem a realização do processo de coleta, organização e representação de dados, acompanhados da interpretação desses dados por noções iniciais da probabilidade.

A investigação estatística apresenta-se, portanto, como uma importante alternativa para o ensino e aprendizagem dos conceitos estatísticos. Segundo Batanero (2001), uma 
investigação diz-se estatística se, na sua concretização, o aluno utiliza metodologias quantitativas, integrando a linguagem e os métodos estatísticos num processo mais global de investigação, ou seja, o ensino de estatística passa a assumir uma perspectiva de cenário investigativo, quando, no seu desenvolvimento, os estudantes estiverem envolvidos na coleta, organização e registro de dados quantitativos.

Considerando cenários investigativos, o papel fundamental da mediação do professor e de colegas pode ser percebido como potencial no desenvolvimento de aprendizagens matemáticas. Na pesquisa (Avi, 2012), são explicitadas questões relacionadas à aprendizagem da matemática através de atividades de investigação estatística, apontando, dentre outras questões, o potencial de atividades de cunho investigativo para a aprendizagem de conceitos. Para este momento, os resultados apresentados tentarão dar conta do papel da mediação no desenvolvimento desse tipo de atividade, na perspectiva de potencializar a significação de conceitos matemáticos e estatísticos.

\section{METODOLOGIA}

Como o enfoque da presente pesquisa é a significação dos conceitos, optamos por trabalhar com um grupo de doze alunos voluntários com idade entre treze e quinze anos, estudantes da $8^{\mathrm{a}}$ série, equivalente ao sétimo ano do ensino fundamental. Foram realizados dez encontros em turno inverso ao horário de aula, no período de abril a junho de 2010. Nestes encontros foi priorizado o trabalho em grupo nos quais os alunos desenvolveram atividades de investigação estatística. Os encontros foram filmados e transcritos pela pesquisadora. As filmagens, juntamente com os registros escritos elaborados pelos alunos e o diário de bordo escrito pela pesquisadora constituem o material empírico da investigação. $\mathrm{O}$ nome dos alunos foi mantido em sigilo, sendo utilizado A para representar os alunos e uma numeração $1,2,3 \ldots$. e Pesq. indicando a pesquisadora. Para a apresentação do material empírico foram utilizados recortes dos encontros denominados aqui de episódios, bem como os diários de campo. Os recortes são fragmentos destes encontros, realizados intencionalmente pela pesquisadora, considerando a problemática da pesquisa, o quadro teórico e sua significação.

A organização das atividades se deu a partir de um projeto proposto por Batanero (2001) e utilizado posteriormente por Sousa (2002). A escolha do tema leva em consideração a grande curiosidade existente por parte dos alunos desta faixa etária em relação ao seu corpo, considerando este tema motivador de discussões e potente em propiciar o envolvimento dos estudantes no processo investigativo.

A proposição da atividade inicial, objeto de discussão deste artigo, foi que os estudantes estabelecessem estratégias para criar um perfil característico do grupo que participava da pesquisa. Com os estudantes organizados em quatro grupos de três componentes, a discussão foi problematizada considerando os questionamentos:

- $\quad$ Como podemos caracterizar os alunos da nossa turma?

- Suponha que temos que apresentar um perfil dos alunos da turma que participam da pesquisa. Como podemos nos organizar para apresentar este perfil?

Através dessa proposição, os estudantes discutiram o que é um perfil, e como determiná-lo, partindo para a segunda etapa que foi a realização de uma entrevista para coleta dos dados. Com os dados em mãos, foi lançada a segunda etapa da investigação, a organização dos dados, com base em questões do tipo: Qual o valor máximo e o valor mínimo dos teus dados? Eles estão espalhados ou concentrados? Qual o valor mais freqüente dos dados, considerando cada questão? Qual o valor do meio? É possível calcular o valor médio dos teus dados. O que isso significa? Como fizeram para encontrá-lo?

$\mathrm{Na}$ etapa seguinte, deveriam elaborar estratégias para representar os dados coletados e analisados anteriormente. Durante todo o desenvolvimento da atividade, diferentes questões inerentes à significação de conceitos estatísticos e matemáticos foram levantadas, e os encaminhamentos foram mediados pela professora/pesquisadora na perspectiva de aprofundar os conceitos a partir da investigação dos alunos.

\section{RESULTADOS E DISCUSSÃO}

As atividades de investigação são tarefas matemáticas abertas, nas quais o aluno não recebe orientações específicas do professor sobre qual resultado deve obter, mas sim, é 
convidado a buscar estabelecer relações, pesquisar, formular estratégias, discutir e apresentar resultados. Por essa característica, a mediação do professor deve se dar de forma consciente e planejada, ou seja, realizar intervenções que possibilitem orientar os modos de pensar dos alunos por intermédio de ações que lhes possibilite apropriar-se de saberes já constituídos culturalmente.

Para Fontana (1996, p.128) a mediação do adulto induz a criança a utilizar e elaborar operações intelectuais, habilidades e estratégias não utilizadas antes, desencadeando processos de desenvolvimento cognitivo. Dessa forma, segundo Vigotski (2001), a mediação do/pelo outro suscita a emergência de funções que, embora a criança não seja capaz de desenvolvê-las sozinha, consegue realizar com o auxílio de outros colegas ou do professor.

Durante os encontros realizados para a produção dos dados, um dos grupos estava discutindo como calcular $70 \%$ de 35 , na perspectiva de tentar identificar qual o total de alunos que tinham 13 anos, considerando a frequiência de (70\%) obtida na coleta dos dados feita por eles, considerando que os alunos que participaram da pesquisa eram uma amostra do total de alunos da turma toda, a qual era constituída de 35 alunos. Na identificação de estratégias, o Grupo 2, após realizar alguns cálculos manuais e com a calculadora, chamou a atenção da turma e da professora, causando um alvoroço ao afirmar que as calculadoras estavam com defeito, já que, ao dividir 6 por 0,5, obtinham como resultado 12. Naquela circunstância isso não era possível, pois, pelas palavras dos alunos "obrigatoriamente, em uma divisão, teriam que obter como resultado um número menor". Aparentemente, o grupo demonstrou reconhecer as características inerentes à divisão por números inteiros, sem considerar que, no caso de divisão por números racionais, estas são diferentes. Esta situação pode ser identificada no episódio abaixo:

\section{Episódio 3 - Parte 1: Divisão de números racionais}

(354) A4 - Olha só, prof.! Tá louca a calculadora (Risos do grupo).

(355) Pesq. - O que houve? Porque você está dizendo isso?

(356) A4 - Tá dando mais, estamos dividindo e tá dando mais (...) (Os demais falam ao mesmo tempo mas não é compreensível).

(357) A8 - Explica pra nós prof. as calculadoras estão todas loucas?

(358) A9 - Assim, ó profe! Eu fui dividir aqui ó (apontando para a folha) e daí era para dar menos mas deu mais, deu doze, a gente dividiu 6 por 0,5 e deu 12. Daí eu fiz na calculadora do A4 e deu também. Tá errado? O que eu fiz de errado?

(359) A4 - Explica, prof.

(360) A8 -É prof. a gente quer entender, tá errado? Fizemos o cálculo certinho um monte de vezes e deu a mesma coisa.

(361) Pesq. - Calma vamos olhar para o cálculo. O que vocês estão fazendo na verdade é a divisão de 6 por 0,5 , certo?

(362) A8-É e deu 12 (Risos).

(363) A9 - É prof. eu não entendi, mas eu fiz certo.

(364) Pesq. - Mas, se vocês fizerem para outros valores, vão verificar que é isso mesmo que acontece, para outros valores também, vocês testaram?

(365) A9 - Sim! Mas por quê?

(366) Pesq. - Aqui vocês estão dividindo por um número decimal, e não por um número inteiro, se vocês usarem o 1/2, que é equivalente a 0,5, e fizerem a divisão, olha só (escrevendo na folha), como a divisão das frações vocês lembram como faz?

(367) A8 - Tá loco ! Fração eu não sei, prof. (Risos do grupo).

(368) A9 - Não lembro, prof.

(369) Pesq. - Para a divisão de duas frações, a gente vai conservar a primeira e multiplicar pelo inverso da segunda.

(370) A4 - Ah, não, é multiplicar em " $x$ ”, prof., assim! (Apontando para a folha fazendo o sinal de $\mathrm{x})$.

(371) Pesq.- Isso! Pode ser também! Então, olha só! Tá vendo o que acontece quando vocês fazem isso? (Referindo-se a divisão; fala enquanto vai fazendo o cálculo).

(372) A8 - Multiplica por dois, dá o dobro, então tá certo!

(373) A9-É tá certo.

(374) Pesq. - Entenderam, a calculadora não está louca! (Pesq. Se afasta para atender outro grupo, porém o grupo continua). 
(375) A4 - Tá certo! Entendi a conta, mas não entendi por quê.

(376) A8-É porque é fração.

(377)- A4 - Tá mas...

(378) A9 - Eu entendi o A4, ele quer saber por quê.

(379) Pesq. - Pessoal, vamos finalizar, continua fazendo os cálculos, A4 chama o teu grupo

para a atividade, quantos alunos representam $70 \%$ de 35? Tô esperando a resposta.

(Chamando todos os grupos para finalizar a atividade).

O episódio nos faz refletir sobre uma importante saliência que se pretende discutir neste artigo: em relação à mediação da professora, na continuação da atividade investigativa.

No turno 366, a professora interrompeu o desejo do grupo em realizar a investigação suscitada na estratégia do grupo e na oportunidade desconsidera a riqueza da curiosidade dos mesmos, talvez pelo avançado do tempo, ou pela determinação do objetivo da atividade, deixando de valorizar um importante momento de investigação. Na sequência da atividade, o grupo continuou a fazer a atividade sugerida, porém sem grandes avanços e, de forma perceptível, sem o mesmo entusiasmo apresentado na discussão anterior, tanto que não levantaram estratégias para serem testadas e nem mesmo finalizaram a atividade.

Vale considerar que em atividades investigativas é papel do professor problematizar o desenvolvimento da atividade, orientar e estimular os alunos no levantamento das hipóteses e estratégias, perceber as dificuldades surgidas e fazer a intervenção necessária, no sentido de reordenar o pensamento do aluno em relação à conjectura levantada, porém, sem desconsiderar as curiosidades dos alunos e os problemas que surgem no decorrer da investigação. Nesse tipo de tarefa, a interação que o professor tem de estabelecer com os alunos [...] é bem diferente da que ocorre em outros tipos de aula, levando-o a confrontar-se com algumas dificuldades e dilemas. (PONTE, BROCADO e OLIVEIRA, 2003, p.47).

Nas interações escolarizadas, o papel do professor e do aluno está socialmente estabelecido, dessa forma, o aluno espera do professor indicações e explicações sobre o andamento da tarefa proposta. A mediação deliberada do professor e o direcionamento dado por este no andamento da atividade deve considerar que a realização da tarefa deve estimular a autonomia e atitude dos alunos, na intencionalidade de atingir os objetivos propostos.

Apesar de acreditar que o espírito investigativo possa motivar a negociação de aprendizagens matemáticas, na oportunidade, a professora desconsiderou o importante passo dado pelos alunos em busca de uma postura investigativa. Ao analisar os diários de campos e os registros dos alunos, refletindo sobre o encontro e dialogando com a orientadora sobre a atividade, optou-se por retomar a discussão do encontro e realizar uma provocação que estimulasse os alunos a investigar o que havia acontecido com a calculadora do colega A9. Situação que foi proposta a partir da seguinte colocação da professora/pesquisadora.

Figura 1: Investigação sobre divisão de números racionais.

O colega A9 precisa da tua ajuda: No encontro anterior a colega A9 estava utilizando a calculadora e ao dividir 6 por 0,5, encontrou como resultado 12. Sua calculadora está com defeito? Investigue discutindo com os teus colegas e lembre-se de registrar as estratégias levantadas.

A atitude inicial dos alunos diante da tarefa proposta foi de estranhamento. A dificuldade estava em admitir que o divisor pudesse ser um número menor que 1 , bem como, sua representação geométrica. Mesmo assim, buscaram levantar conjecturas, sem sucesso. $\mathrm{O}$ episódio a seguir traz à tona as intervenções feitas pela professora/pesquisadora na perspectiva de mediar a investigação.

\section{Episódio 4 - Parte 3 - Dividindo 6 por 0,5}

(256) Pesq. - Pessoal! Atenção aqui; acho que vocês estão confundindo no desenho. O que a gente tá tentando responder? (Pesq. Chama a atenção de toda a turma para realizar o questionamento)

(257) A2 - Se a calculadora do A9 tava certa.

(258) Pesq. - Isso, mas com qual operação?

(259) Alunos - Dividindo 6 por 0,5 (Mais de um aluno responde, não se podendo identificar qual foi na gravação). 
(260)Pesq. - Percebam, pessoal, que vocês estão a comparar quantas vezes o 0,5 cabe no 6? Não é isso? (Os alunos permanecem em silêncio e a pesquisadora repete o questionamento).

(261) A8 - Cabe 12, prof. (Mais colegas confirmam a resposta do A9).

(262) A2 - Então é isso! É o que dá na calculadora, 12!

(263) A8 - Então aqui a gente, quando divide, tá vendo quantas metades vão caber no 6, que são 12. Aumenta, pois cabem mais metades em cada um.

(264) A2 - Duas metades para cada um.

Até o momento, o grupo estava representando a divisão com base nas definições do senso comum, atribuídas a divisão. Para tanto, as colocações da professora em organizar as conjecturas levantadas pelos alunos foram pertinentes e fundamentais para a significação da divisão por números racionais, estabelecida posteriormente pelos alunos.

O questionamento feito após ter havido a investigação facilitou para que alguns alunos abstraíssem a ideia trabalhada, considerando o significado de dividir um número inteiro por um número racional, ou seja, que na realidade está sendo dividido um número inteiro em partes. Mesmo após a intervenção, e após termos realizado algumas representações geométricas, exemplificando, por exemplo, quantas vezes um inteiro cabe em um meio, alguns alunos evidenciaram que ainda apresentavam algumas dúvidas quando foram feitas outras intervenções por parte dos próprios colegas nas quais reproduziram as representações anteriormente realizadas pela professora/pesquisadora para que pudessem sistematizar a propriedade discutida.

As intervenções da professora foram na perspectiva de propor que os alunos observassem a divisão por meios. Para Fontana (1996), nas interações sociais, a mediação do adulto ocorre espontaneamente através da utilização da linguagem. Já, quando estamos lidando com interações escolarizadas que estão organizadas na perspectiva de desenvolver aprendizagens, o processo é diferente, dado que a mediação deixa de ser somente espontânea e passa a ser intencional e dirigida pelo adulto, no caso a professora. Na situação, o uso da representação por meio de frações foi a ferramenta utilizada pela professora. Também o uso da simplificação por meio da multiplicação por 10 eliminando as casas decimais poderiam ter facilitado a compreensão, apontando para a evidência de que estava sendo dividido 60 por 5, possibilitando a discussão do conceito de equivalência.

Apesar de a tarefa ter um grau de estruturação aberto, a professora tinha claros os objetivos a atingir e suas falas se deram na perspectiva de potencializar a investigação e não rompê-la. Essa é a principal diferenciação entre o primeiro e o segundo episódios. No primeiro, a professora dá a explicação ao grupo, deixando de valorizar as estratégias levantadas e de considerá-la em suas falas. Já no segundo, potencializa a investigação a partir de suas intervenções. A exigência de tempo, oriunda da estruturação curricular, muitas vezes, leva o professor a apresentar dificuldades na hora de potencializar uma atividade. Ter claro quais os objetivos daquele objeto de ensino se faz fundamental para que possa priorizar a formação de conceitos.

Pode-se sugerir que, ao auxiliá-los, a professora estimulou o desenvolvimento de conhecimentos que podem fazer parte dos conhecimentos potenciais do aluno considerando que, segundo Pino (2000), a linguagem (fala) desempenha papel relevante no processo de mediação da aprendizagem.

A discussão exposta nos episódios nos leva a crer que, no contexto do ensino, o professor pode buscar atuar em zonas de desenvolvimento proximal (ZDP). Esse conceito é definido por Vigotski (1989), como sendo o caminho entre o que se consegue fazer sozinho e o que está próximo de se fazer sozinho. Assim, a ZDP

[...] é a distância entre o nível de desenvolvimento real, que se costuma determinar através da solução independente de problemas, e o nível de desenvolvimento potencial, determinado através da solução de problemas sob a orientação de um adulto ou em colaboração com companheiros mais capazes (VIGOTSKI, 1989, p.128). 
Considerando as relações pedagógicas, esse conceito tem uma importante repercussão no campo educacional. Já que, ao trabalhar coletivamente, o aluno é capaz de desenvolver funções mentais superiores e a interação e a mediação são percebidas como potenciais no desenvolvimento da aprendizagem. Isso pode ser observado nos turnos 260 a 264, quando chamar atenção para a pergunta fez com que o aluno percebesse qual o significado do resultado obtido pela calculadora. Assim, o ensino da matemática, baseado na coletividade e no estímulo de parcerias, pode ser caracterizado como potencial na sala de aula, articulando e desencadeando de fato a aprendizagem.

Ao trabalhar coletivamente, quando não consegue desenvolver determinada atividade sozinho, o aluno pode tentar repetir uma ação realizada pelo professor ou por outro colega mais desenvolvido. A repetição no espaço simbólico da ZDP é, porém, entendida como motivadora de aprendizagens.

Para imitar, é necessário possuir os meios para se passar de algo que já se conhece para algo novo. Com o auxílio de uma outra pessoa, toda criança pode fazer mais do que faria sozinha - ainda que se restringindo aos limites estabelecidos pelo grau de seu desenvolvimento (VYGOTSKY, 1989, p.129)

No turno 264, o aluno traz para a discussão a fala da professora, argumentando quantas metades cabem em um inteiro, tendo a fala complementada pelo colega no turno A8, dando indícios de que estavam a significar a representação realizada. Ao repetir, o sujeito está sendo estimulado a avançar seu nível de desenvolvimento atual, realizando situações que estimulem a aprendizagem. Para que haja aprendizagem, é importante que o aluno avance, concebendo que "[...] o único tipo positivo de aprendizagem é aquele que caminha à frente do desenvolvimento, servindo-lhe de guia; deve voltar-se não tanto para as funções já maduras, mas principalmente para as funções em amadurecimento" (VIGOTSKI, 1989 p.130).

A aprendizagem pode ser promovida através de atividades que estimulem a interação entre alunos e entre professor e alunos. Foi nesta perspectiva que se colocaram as intervenções da professora. O planejamento, análise, (re)planejamento e a mediação contribuíram para a aprendizagem dos alunos considerando o espaço simbólico da ZDP.

\section{CONCLUSÃO}

Os episódios selecionados apresentam os alunos em uma atividade de investigação estatística no momento em que estes estavam buscando significar a divisão por um número racional. O levantamento de estratégias os fez evoluir na investigação, porém, sozinhos não estavam dando conta da significação. As intervenções da professora foram fundamentais na continuação da atividade, concebendo que a aprendizagem humana é socialmente constituída e a interação em sala de aula dá conta de uma rica possibilidade para o desenvolvimento de funções até então não desenvolvidas, ampliando o desenvolvimento atual a fim de potencializálo.

Os ambientes de investigação exigem do professor uma postura diferenciada diante da concepção da construção de aprendizagens matemáticas, considerando que a mediação do professor é fundamental para o desenvolvimento da significação de conceitos matemáticos, já que este poderá oferecer-lhe o suporte necessário para a compreensão da atividade proposta.

Nas duas intervenções a professora agiu de forma diferente. $\mathrm{Na}$ segunda, os questionamentos feitos possibilitaram a significação dos conceitos trazidos a discussão. A mediação do professor é, portanto, fundamental no desenvolvimento de aprendizagens. Dessa forma, o refletir sobre a própria prática na sequência dos encontros foi fundamental para que a professora tomasse conta dessa importante saliência que surgiu em decorrência de sua prática.

Consideramos que para que a realização de uma investigação culmine no desenvolvimento de aprendizagens matemáticas tanto o professor quanto os alunos não podem transmitir aos demais seus modos de pensar, mas, sim, lhes explicitar sua forma de compreensão através de signos que podem coincidir com a compreensão do outro, e assim promover a discussão da atividade. Dessa forma, principalmente em atividades de investigação, a atenção e mediação deliberada do professor são fundamentais no desenvolvimento de aprendizagens, podendo sua pratica ser estruturada com base nessa perspectiva sempre 
valorizando o desenvolvimento dos alunos e intervindo de forma a potencializar a aprendizagem.

\section{REFERÊNCIAS}

[4] AVI, Emanueli Bandeira. Aprendizagens matemáticas desenvolvidas em ambiente de investigação estatística. Dissertação de Mestrado em Educação nas Ciências. Unijui. Ijuí. 2012

[3] BATANERO, Carmen. Didáctica de la estadística. Granada: GEEUG, Departamento de Didáctica de la Matemática, Universidad de Granada, 2001.

[3]BRASIL. Ministério da Educação. Secretaria de Educação Fundamental. Parâmetros Curriculares Nacionais: Matemática - Ensino Fundamental - $3^{\circ}$ e $4^{\circ}$ Ciclos. Brasília, 1998.

[3]FONTANA, Roseli A. Cação. Mediação pedagógica na sala de aula. São Paulo. Autores Associados. 1996. (Coleção educação contemporânea)

[2]LOPES, Celi Aparecida Espasandin. A Educação Estatística no currículo de Matemática: um ensaio teórico.In: REUNIÃO ANUAL DA ANPED, 33., 2010, Caxambu. Anais... caxambu, 2010. p. 1-15.

[3]LOPES, Celi. E. COUTINHO, Cileda. Leitura e Escrita em Educação Estatística. IN: LOPES Celi E.; NACARATO, Adair. Educação Matemática, Leitura e Escrita: armadilhas, utopias e realidade. Campinas/SP: Mercado e Letras, 2009, PP. 61- 78.

[1]PINO, Angel Sirgado. O conceito de mediação semiótica em Vygotsky e seu papel na explicação do psiquismo humano. In: Caderno Cedes, ano XX, nº 85, julho/2000, p. 39-51.

[3]PONTE, João Pedro da; BROCADO, Joana; OLIVEIRA Hélia. Investigações matemáticas na sala de aula Belo Horizonte: Autêntica, 2003 (Coleção Tendências em Educação Matemática).

[2]SOUSA, Olivia de. Investigações estatísticas no $6^{\circ}$ ano. In: GTI (Org.). Refletir e investigar sobre a prática profissional. Lisboa: APM, pp. 75-97, 2002. Disponível em www.educ.fc.ul.pt/docentes/jponte/fdm/textos/sousa\%2002.pdf. acesso em 12/02/12.

[3]VIGOTSKI, L. V. A Construção do pensamento e da linguagem. Tradução de Paulo Bezerra. São Paulo: Martins Fontes, 2001.

[3]VIGOTSKI, L.V. Pensamento e linguagem. Tradução de Jéferson Luiz Camargo. São Paulo: Martins Fontes, 1989. 